\title{
International confidence spillovers and business cycles in small open economies
}

\author{
Michał Brzoza-Brzezina ${ }^{1}$. Jacek Kotłowski ${ }^{2}$ (D)
}

Received: 25 March 2019 / Accepted: 13 May 2020 / Published online: 13 June 2020

(c) The Author(s) 2020

\begin{abstract}
The economic literature has for a long time been looking for explanations of a very strong international correlation of business cycles. This paper shows empirically that common fluctuations can to some degree be the effect of confidence shocks being transmitted internationally. We focus on a large (euro area) and a small, nearby economy (Poland). Our results show that euro area confidence fluctuations account for approximately 40-70\% of business cycle fluctuations both in the euro area and in Poland. More importantly, their transmission happens not only via traditional channels (e.g., by confidence affecting euro area GDP and then Polish GDP via trade), but to a large extent occurs directly (e.g., by news spreading via media).
\end{abstract}

Keywords International spillovers - Animal spirits $\cdot$ Sentiments $\cdot$ Business cycle

JEL Classification C32 · E32 · F44

\begin{abstract}
This project was financed by the National Science Centre Grant No. 2017/25/B/HS4/01429. The views expressed herein are ours and not necessarily those of Narodowy Bank Polski or SGH Warsaw School of Economics. We would like to thank Paul Beaudry, Fabio Milani, Nitya Pandalai-Nayar, Fabien Rondeau, Harald Uhlig and Grzegorz Szafrański for useful discussions. Comments received at the Conference on Computational and Financial Econometrics, ISCEF Conference, ICMAIF Conference, Applied Economics Meeting and the seminar at Narodowy Bank Polski are gratefully acknowledged as well. We also wish to thank Patrycja Beniak and Róża Lewińska for their help in obtaining parts of the data.
\end{abstract}

\footnotetext{
$凶$ Jacek Kotłowski

jkotlo@sgh.waw.pl

Michał Brzoza-Brzezina

mbrzez@sgh.waw.pl

1 Department of Quantitative Economics, SGH Warsaw School of Economics, Al. Niepodleglości 162, 02-554 Warsaw, Poland

2 Institute of Econometrics, SGH Warsaw School of Economics, Al. Niepodległości 162, 02-554 Warsaw, Poland
} 


\section{Introduction}

Cyclical economic fluctuations can originate in (possibly nonfundamental) shifts in expectations about economic activity. This idea goes back at least to Pigou (1927) and Keynes (1936), who postulated that waves of optimism or pessimism might influence current economic conditions. For many years mainstream macroeconomic models have largely ignored the role of such factors as drivers of business cycles. More recent literature, both empirical and theoretical, attempts to formalize and quantify the impact of fluctuations in moods. As will be shown below, most studies document a highly significant role of such factors.

An important, related and highly relevant question is, whether confidence also spills over borders and affects cyclical fluctuations abroad. The importance and relevance of this question stems from three observations. First, that economic fluctuations between countries are highly correlated, so that obviously business cycles spill over borders (e.g., Gong and Kim 2018). Second, that confidence indicators are highly correlated across countries as well (Ha et al. 2020). Third, that the literature (with special emphasis on structural macroeconomic models) has a clear problem with explaining where such high correlation comes from. Neither the international real business cycle model (Backus et al. 1992) nor new Keynesian models (Justiniano and Preston 2010) can explain the high correlation of business cycles, unless productivity shocks are assumed to be correlated. Trade seems by far not sufficient to explain comovement, adding financial factors helps somewhat (Olivero 2010; Brzoza-Brzezina et al. 2018), but international correlations still remain a puzzle. ${ }^{1}$ This paper investigates the role of confidence in driving the international comovement of economies.

The literature on the role of confidence in driving cyclical fluctuations in a closed economy context is abundant. We use it to define the main concepts. Contemporaneous papers (at least a substantial share) distinguish two types of confidence shocks (see e.g., Barsky and Sims 2012).

The first relates to new information about future technology that is orthogonal to current technology. In the literature such shocks are usually called "technology news shocks", and we will stick to this convention throughout the paper. One can think for instance of innovations that have already been invented (and are known to agents), but due to implementation lags have not yet been implemented and thus do not increase productivity yet. These shocks have a supply-side flavor-ultimately they are supposed to increase productivity and, as a result, are expected to have a permanent impact on output. The related literature originates from the paper of Beaudry and Portier (2006), who empirically document the existence of a shock (derived from stock price data) that causes a boom in investment and consumption and significantly precedes the growth of productivity. Beaudry and Portier (2004) include this type of shock (a signal about future technology) into an RBC model. Fujiwara et al. (2011) estimate a New Keynesian model with technology news shocks and Blanchard et al. (2013) additionally consider noise (i.e., false) shocks about future technology. Schmitt-Grohe and Uribe (2012) generalize the concept to a wider range of shocks. They estimate a DSGE model

\footnotetext{
${ }^{1}$ See Gong and Kim (2018) for an empirical assessment of the role played by trade and financial linkages for business cycle synchronization.
} 
with several news shocks and confirm a very important role of anticipated shocks in driving main business cycle variables. Kamber et al. (2017) estimate VAR models for four developed, small, open economies and documents that technology news shocks explain a substantial part of output fluctuations (between 6\% in New Zealand and 40\% in the UK). Further contributions to the empirical stream in the literature include i.a. Barsky and Sims (2011), who estimate a new Keynesian type of model that allows for technology news shocks and show that their contribution to explaining the variance of consumption and investment, while negligible in the short run, increases to $50 \%$ in the long run. On the theoretical front Jaimovich and Rebelo (2009) discuss the conditions under which news shocks can generate comovement of main macrovariables characteristic for business cycle fluctuations. Their main conclusion is that wealth effects must be weak, since otherwise positive news shocks reduce current labor supply and, hence current output. Eusepi and Preston (2011) develop a model that departs from the rational expectations assumption towards learning, in which self-fulfilling expectations arise in response to technology shocks.

The second type of confidence shocks relates to nonfundamental shifts in demand (consumption, investments), due to expectations about future prospects of the economy. It bears similarities Keynes' notion of "animal spirits" that influence entrepreneurs willingness to undertake investment activity and, hence, drive cyclical fluctuations. Following part of the literature we will refer to such shocks as "sentiment shocks". ${ }^{2}$ These shocks are purely demand-driven, and, as such are expected to have only a temporary impact on economic activity. ${ }^{3}$ Again, both empirical and theoretical studies exist that deal with these shocks. Angeletos and La'O (2013) provide a model in which limited communication between agents provides an environment in which shocks to believes (sentiments) have real effects that resemble boom-bust phenomena. Angeletos et al. (2018) derive a main business cycle factor from US data and show that its properties differ from shocks known in the structural literature. In particular, the factor moves output, hours worked, consumption and investments in the same direction, without affecting technology. Then, the paper constructs and estimates a DSGE model with a shock to agent's believes about other agents perception of business conditions. This shock is interpreted as a sentiment shock and has properties similar to the empirically derived factor and is shown to explain 40-50\% of the variance of output, consumption and investment. Milani (2017) estimates a DSGE model with learning and shows that sentiment fluctuations are responsible for over $40 \%$ of business fluctuations in the US. On the other hand, according to the Barsky and Sims (2011) estimation, sentiment shocks have a negligible impact on output and consumption for both short and long horizons (technology news is what counts).

Three papers (to our knowledge) dealt explicitly with the role of confidence in explaining international business cycle correlations. Beaudry et al. (2011) extend the model of Beaudry and Portier (2004) to a two-country setting. They show that technology news shocks can drive cross-country synchronization of cycles even in a flexible price economy. Levchenko and Pandalai-Nayar (2020) take an empirical approach to

\footnotetext{
2 Some papers call this type of shock "confidence shock". We call it "sentiment", while leaving the term "confidence" to encompass both sentiment and news innovations.

3 In our SVAR framework these shocks can be technically interpreted as shocks to expectations of future GDP which are not justified by current economic conditions as reflected by the behavior of model variables.
} 
assess the spillover of confidence shocks between the US and Canada. They identify both technology news and sentiment shocks and show that the Canadian business cycle is driven to a large extent by US confidence. DeGrauwe and Ji (2017) construct a two-country model with agents switching endogenously between two forecasting rules (fundamentalist and extrapolative). In this framework, small spillovers via trade channels are amplified by the animal spirit mechanism resulting from agents becoming extrapolative in case of boom or bust.

Our paper deals directly with the last issue: whether, to what extent and how does confidence affect the international transmission of business cycles? We estimate a SVAR/VECM model based on data from Poland and the euro area (a small open economy and its large neighbor). The contribution of our paper to the literature is threefold. First, we check whether the earlier findings for US-Canada (Levchenko and PandalaiNayar 2020) spillovers are universal, in that they also hold for a large-small economy pair in a different part of the world. Importantly, in contrast to the US-Canada pair, Poland and the euro area (EA) are not at a similar level of development, ${ }^{4}$ so we also check whether spillovers of technology news matter in such case as well. Second, and more importantly, our paper distinguishes between indirect (via trade or financial linkages) and direct (via cross-border spread of news) spillovers of confidence. Third, our econometric approach is based on a cointegrating relationships, which allow to better capture low-frequency movements in the data. As a consequence we offer a contribution to the cited above literature searching for the "missing transmission channel" between countries.

Our main findings are as follows. First, we confirm the important role of confidence in driving the business cycle in the euro area. At the 12 quarter horizon confidence shocks account for $38 \%$ of forecast error variance decomposition of GDP in the euro area (70\% at the 4-quarter horizon). Second, spillovers from the euro area to Poland do matter as well: at the 12-quarter horizon foreign confidence shocks determine $75 \%$ of GDP fluctuations in Poland (64\% at the 4-quarter horizon). Our distinction of direct (e.g., via media) and indirect (e.g., via trade or financial channels) spillovers shows that (depending on the shock and horizon) $20-50 \%$ of the spillovers happens directly. As a result, at the 4 quarter horizon $25 \%$ (and $15 \%$ at the 12 quarter horizon) of the variance of Polish GDP is explained by direct spillovers of confidence (news and sentiment) from the euro area. This is our account of the "missing channel" in the structural business cycle literature. Third, we analyze historical shock decompositions. These show periods where confidence shocks were particularly important. In the euro area, sentiment shocks played a significant role i.e., in generating the slowdown during the financial crisis, but had a positive impact on GDP after the ECBs announcement of the Outright Monetary Transactions programme in 2012, which calmed financial markets and substantially brought down country risk premia. These events contributed to business cycle fluctuations in Poland as well.

The rest of the paper is organized as follows. Section 2 discusses the estimation strategy and the data, Sect. 3 the results, Sect. 4 offers a number of robustness checks and Sect. 5 concludes.

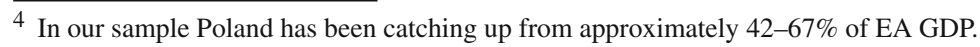




\section{Model, data and estimation}

\subsection{Model}

We investigate the international spillovers of technology and sentiment shocks using a structural vector autoregression (SVAR) framework. We follow the approach proposed initially by Uhlig (2004) and applied in the confidence literature by Barsky and Sims (2011), Levchenko and Pandalai-Nayar (2020) and Angeletos et al. (2018) and identify the structural shocks by imposing so-called medium-run restrictions on the impact matrix.

Our basic VAR model includes seven variables for the large economy (euro area): total factor productivity (TFP), real GDP, hours worked, short term nominal interest rate, investments, private consumption and GDP forecasts and GDP for the small open economy (Poland) - in this order. We identify three structural shocks in the model, all stemming from the euro area, which also affect Poland as the economy tightly integrated with the euro area.

The method we apply relies on the sequential identification of the subsequent shocks. We extract the respective shocks conditional on the values of the previous shocks. As a first step, we extract two technology shocks in the euro area in the spirit of Barsky and Sims (2011). The first one will be called surprise technology shock and corresponds to the reduced form innovation to the TFP equation in the VAR model with the TFP variable ordered first. The second one is a news shock about future TFP which we identify as having no contemporaneous impact on TFP but explaining the maximum of the forecast error variance of the TFP series after accounting for the impact of the surprise technology shock. This approach reflects the assumption that TFP in the euro area is affected by these two shocks only:

$$
\mathrm{TFP}_{t}=\lambda_{1}^{\mathrm{TFP}} \epsilon_{t}^{\mathrm{sur}}+\lambda_{2}^{\mathrm{TFP}} \epsilon_{t-s}^{\text {news }}
$$

where $\mathrm{TFP}_{t}$ is TFP in the euro area and $\epsilon_{t}^{\text {sur }}$ and $\epsilon_{t}^{\text {news }}$ are the surprise and news technology shocks, respectively.

Finally, we identify the sentiment shock in the euro area. Our identification procedure is closely linked to the method proposed by Levchenko and Pandalai-Nayar (2020) who investigate the spillovers of confidence shocks from US to Canada. Like in this approach we identify sentiment as the shock which maximizes the forecast error variance of the GDP forecasts after accounting for surprise and news technology shocks:

$$
\mathrm{GDP}_{t}^{F, \mathrm{EA}}=\lambda_{1}^{F} \epsilon_{t}^{\text {sur }}+\lambda_{2}^{F} \epsilon_{t-s}^{\text {news }}+\lambda_{3}^{F} \epsilon_{t}^{\text {sent }}+\zeta_{t}
$$

where $\epsilon_{t}^{\text {sent }}$ is the sentiment shock in the euro area, while $\zeta_{t}$ is another shock (or combination of structural shocks) affecting the expectations of future economic activity in the euro area $\mathrm{GDP}_{t}^{F, \text { EA }}$ not related to technology or sentiment. Hence, our approach does not exclude that some other shocks may also affect agents expectations about future economic activity. 
In what follows, the identification procedure is described in detail. We start with the reduced form $\operatorname{VAR}(p)$ model:

$$
A(L) Y_{t}=u_{t}
$$

where $Y_{t}$ is the $k \times 1$ vector of observable variables in levels and $u_{t}$ is a vector of reduced form disturbances.

The moving average representation of model (3) is:

$$
Y_{t}=B(L) u_{t}
$$

We assume that the reduced form disturbances $u_{t}$ are linear combinations of structural shocks $\epsilon_{t}$ with the impact matrix $C_{0}$ :

$$
u_{t}=C_{0} \epsilon_{t}
$$

Therefore the structural representation of the $\operatorname{VAR}(p)$ model is:

$$
Y_{t}=C(L) \epsilon_{t}
$$

where $C(L)=B(L) \cdot C_{0}$. We assume that the structural shocks $\epsilon_{t}$ are orthogonal to each other and have unit variance, which implies that:

$$
C_{0} C_{0}^{\prime}=\Sigma
$$

where $\Sigma$ is the covariance matrix of reduced form innovations $u_{t}$.

As is well-known there is an infinite number of matrices satisfying condition (7). For example the Cholesky decomposition of $\Sigma$ provides a lower triangular matrix which fulfills condition (7) and this matrix, denoted as $\tilde{C}_{0}$ is the starting point for the structural decomposition with medium run restrictions.

As a next step we specify matrix $D$, which satisfies the restriction $D D^{\prime}=I$ and which defines the impact matrix $C_{0}$ as $C_{0}=\tilde{C}_{0} D$.

The subsequent columns of matrix $D$ correspond to the identified structural shocks. The identification of the respective columns of matrix $D$ is based on the assumption that the structural shocks $\epsilon_{t}$ explain the maximum variance of the forecast error of selected variables in the $\operatorname{VAR}(p)$ model. Below we discuss the subsequent steps of our decomposition.

The h-step ahead forecast error from the $\operatorname{VAR}(p)$ model can be derived as:

$$
Y_{t+h}-\hat{Y}_{t}(h)=\sum_{\tau=0}^{h} B_{\tau} u_{t+h-\tau}=\sum_{\tau=0}^{h} B_{\tau} C_{0} \epsilon_{t+h-\tau}=\sum_{\tau=0}^{h} B_{\tau} \tilde{C}_{0} D \epsilon_{t+h-\tau}
$$

where $\hat{Y}_{t}(h)$ is the h-step ahead forecast of $Y_{t}$ while $B_{\tau}$ is the respective coefficient matrix in the moving average representation of $\operatorname{VAR}(p)$. 
Accordingly the h-step ahead forecast error of variable $i$ in vector $Y_{t}$ is:

$$
Y_{i, t+h}-\hat{Y}_{i, t}(h)=\sum_{\tau=0}^{h} B_{i, \tau} \tilde{C}_{0} D \epsilon_{t+h-\tau}
$$

where $B_{i, \tau}$ is the $i$ th row of matrix $B_{\tau}$. Then the forecast error variance of variable $i$ at horizon $h$ is:

$$
\Omega_{i}(h)=\sum_{\tau=0}^{h} B_{i, \tau} \Sigma B_{i, \tau}^{\prime} .
$$

Let $\Omega_{i, j}(h)$ denote the contribution of the structural shock $j$ to the forecast error variance of variable $i$ at horizon $h$ :

$$
\Omega_{i, j}(h)=\frac{\sum_{\tau=0}^{h} B_{i, \tau} \tilde{C}_{0} d_{j} d_{j}^{\prime} \tilde{C}_{0}^{\prime} B_{i, \tau}^{\prime}}{\sum_{\tau=0}^{h} B_{i, \tau} \Sigma B_{i, \tau}^{\prime}}
$$

where $d_{j}$ is the $j$ th column of matrix $D$.

Without loss of generality let us assume that the first two structural shocks are the euro area surprise and news technology shocks and the third one is the euro area sentiment shock. The baseline of the identification proposed by Barsky and Sims (2011) and adopted in our paper is the assumption expressed by (1) that only two technology shocks influence TFP for the euro area. This assumption implies:

$$
\Omega_{1,1}(h)+\Omega_{1,2}(h)=1 \forall h .
$$

The surprise technology shock is the reduced form innovation in the TFP equation in model (3), while the news technology shock is the shock, which maximizes the forecast error variance of TFP over $H^{\text {news }}$ horizon after accounting for the impact of the surprise technology shock.

The maximization problem can be written as follows (see Barsky and Sims 2011):

$$
d_{2}=\operatorname{argmax} \sum_{h=0}^{H^{\text {news }}} \Omega_{1,2}(h)=\operatorname{argmax} \sum_{h=0}^{H^{\text {news }}}\left(\frac{\sum_{\tau=0}^{h} B_{1, \tau} \tilde{C}_{0} d_{2} d_{2}^{\prime} \tilde{C}_{0}^{\prime} B_{1, \tau}^{\prime}}{\sum_{\tau=0}^{h} B_{1, \tau} \Sigma B_{1, \tau}^{\prime}}\right)
$$

s.t.

$$
\begin{aligned}
& \tilde{C}_{0}(1, j)=0 \forall j \neq 1 \\
& d_{2}(1)=0 \\
& D^{\prime} D=I
\end{aligned}
$$

where $d_{2}$ is the second column of $D$ matrix, which specifies the second structural shocks interpreted here as the news technology shock. Therefore $\tilde{C}_{0} d_{2}$ is the impact vector of this shock. The first two restrictions guarantee that the news shock does not 
have a contemporaneous effect on TFP. The third constraint ensures that vector $d_{2}$ is a column of an orthonormal matrix.

Uhlig (2004) shows that the maximization problem defined by (13) is equivalent to finding the eigenvector (which is a non-zero portion of $d_{2}$ ) associated with the largest eigenvalue of the lower $(k-1) \times(k-1)$ submatrix of matrix $\Lambda^{\text {news }}$, which is a weighted sum of the matrices $\left(B_{1, \tau} \tilde{C}_{0}\right)^{\prime}\left(B_{1, \tau} \tilde{C}_{0}\right)$ over $H^{\text {news }}$ :

$$
\Lambda^{\text {news }}=\sum_{\tau=0}^{H^{\text {news }}}\left(H^{\text {news }}+1-\max (1, \tau)\right)\left(B_{1, \tau} \tilde{C}_{0}\right)^{\prime}\left(B_{1, \tau} \tilde{C}_{0}\right)
$$

Next, we identify the euro area sentiment shock, assumed to maximize the remaining forecast error variance of the euro area GDP forecast over $H^{\text {sent }}$ horizons after accounting for the contribution of surprise and news technology shocks. The forecast horizon set for the identification of the sentiment shock is assumed to be shorter than the horizon chosen to identify the technology shocks since the impact of the sentiment shock on GDP is supposed to be temporary (this is a demand shock). As already mentioned we assume that the euro area GDP forecast is ordered seventh in the $\operatorname{VAR}(p)$ model while the sentiment shock is the third structural shock. It is worth to note that the identification of the sentiment shock does not alter two technology shocks specified in the previous step. Thus the contribution of these shocks to the forecast error variance of GDP forecast is fixed for all horizons.

To identify the sentiment shock we derive vector $d_{3}$ by solving the following equation:

$$
d_{3}=\operatorname{argmax} \sum_{h=0}^{H^{\text {sent }}} \Omega_{7,3}(h)=\operatorname{argmax} \sum_{h=0}^{H^{\text {news }}}\left(\frac{\sum_{\tau=0}^{h} B_{7, \tau} \tilde{C}_{0} d_{3} d_{3}^{\prime} \tilde{C}_{0}^{\prime} B_{7, \tau}^{\prime}}{\sum_{\tau=0}^{h} B_{7, \tau} \Sigma B_{7, \tau}^{\prime}}\right)
$$

s.t.

$$
\begin{array}{r}
\tilde{C}_{0}(1, j)=0 \forall j \neq 1 \\
D(:, 2)=\hat{d}_{2} \\
D^{\prime} D=I .
\end{array}
$$

The vector $d_{3}$ defining the euro area sentiment shock is thus the third column of matrix $D$. We solve Eq. (15) subject to the constraints that the second column of matrix $D$ is fixed and equal to the impact vector corresponding to the news shock $\hat{d}_{2}$ identified in the previous step. Numerically we find vector $d_{3}$ by proceeding as follows:

1. We form a matrix $D^{\text {news }}=\left[\begin{array}{cc}1 & 0 \\ 0 & \tilde{D}^{\text {news }}\end{array}\right]$, where the subsequent columns of matrix $\tilde{D}^{\text {news }}$ are the eigenvectors associated with the eigenvalues (set in descending order) being the solution to problem (13). 
2. We derive matrix $\Lambda^{\text {sent }}$, as:

$$
\Lambda^{\mathrm{sent}}=\sum_{\tau=0}^{H^{\mathrm{sent}}}\left(H^{\mathrm{sent}}+1-\max (1, \tau)\right)\left(B_{7, \tau} \tilde{C}_{0} D^{\mathrm{news}}\right)^{\prime}\left(B_{7, \tau} \tilde{C}_{0} D^{\mathrm{news}}\right) .
$$

3. We calculate the eigenvectors corresponding to the eigenvalues of the lower $(k-2) \times(k-2)$ submatrix of matrix $\Lambda^{\text {sent }}$. These eigenvectors are set to be the subsequent columns of $(k-2) \times(k-2)$ matrix $\tilde{D}^{\text {sent }}$.

4. We derive a $k \times k$ matrix $D^{\text {sent }}=D^{\text {news }}\left[\begin{array}{ccc}1 & 0 & 0 \\ 0 & 1 & 0 \\ 0 & 0 & \tilde{D}^{\text {sent }}\end{array}\right]$.

5. The vector $d_{3}$ which corresponds to the euro area sentiment shock is the third column of $D^{\text {sent }}$ matrix.

Angeletos et al. (2018) construct and estimate a structural DSGE model with structural sentiment shocks and show that those are closely related to a main business cycle shock extracted from a VAR model. The latter is identified using a sequential identification scheme (by maximizing the variance of output and hours worked). The paper shows that the empirical and structural shocks share the same properties (in terms of impulse responses they generate) and have very similar time series. Given the relationship to theory the properties of the empirical shock evidenced by Angeletos et al. (2018) are exactly what we expect from our extracted sentiment shock. After our estimation has been done, we carefully check whether our estimated shock shares these properties.

\subsection{Data}

As already mentioned we estimate the model for the euro area (EA) and Poland (PL). Poland is strongly integrated with the euro area (which buys almost $60 \%$ of its exports). At the same time it is relatively small-at current prices Polish GDP amounts to less than $5 \%$ of the euro area. They are close in geographic and political terms (both are part of the European Union). Moreover, existing research documents a high level of business cycle correlation (e.g., Stanisic 2013). Summing up, Poland and the euro area seem to be ideal candidates to look for a significant role of confidence spillovers between a large and small economy. Moreover, GDP per capita and productivity in Poland were in our sample much lower than in the euro area. For instance GDP per capita measured at purchasing power standards increased from $42 \%$ of the EA level in 2000 to $67 \%$ in 2016. This means that in the period under consideration Poland can be treated as an importer of technology rather than innovator, validating our decision to identify technology shocks only in the euro area.

The estimated model consists of eight variables: total factor productivity (EA), real GDP (EA and PL), hours worked (EA), real investments (EA), real private household consumption (EA), GDP forecast of professional forecasters (EA) and the short term nominal interest rate (EA). We use GDP forecasts from the Survey of Professional Forecasters (SPF) ranging two quarters ahead. Given that the euro area hit the zero lower bound on interest rates we decided to use the shadow rate calculated using 
the method of Wu and Xia (2016) (series available from Cyntia Wu's web page) since 2004 and EURIBOR3M before. Total factor productivity (adjusted for capacity utilization) is calculated by the European Commission (Havik et al. 2014) and has been interpolated to quarterly frequency using quadratic frequency conversion filter. The model is estimated with quarterly data from 1Q1999 until 4Q2016. The beginning of our sample is motivated both by the creation of the euro area and introduction of inflation targeting in Poland.

\subsection{Estimation}

We are now ready to estimate the model and extract the structural shocks. In contrast to Levchenko and Pandalai-Nayar (2020) we specify the model as a Vector Error Correction Model (VECM) to better capture the medium- and long run relationships between the variables. We set the maximum lag order in the VECM equal to 1 as indicated by $\mathrm{BIC}$ information criterion. The Johansen trace and maximum eigenvalue tests suggest that the number of cointegrating vectors spanning the cointegrating space is between three and five. We were able to identify four economically justified long-run relationships and so decided to set the number of cointegrating relations to four. Accordingly we impose restrictions on the cointegrating vectors to identify the whole cointegrating space. We identify the first cointegrating vector as a one-factor production function for the euro area and we restrict GDP as a function of TFP (with unit elasticity) and hours worked. The estimated long run elasticity of GDP with respect to hours worked amounts close to 0.8 . The second cointegrating relation links the GDP forecast for the euro area to current GDP. The estimate of the respective parameter in the cointegrating vector is slightly above one, which reflects the fact the forecasters expected on average a positive GDP growth rate over the sample. ${ }^{5}$ The third cointegrating vector is a longterm investments equation, which relates euro area investments positively to the GDP forecast and negatively to the interest rate. The last cointegrating vector constitutes a long term technology transmission channel from the euro area to Poland. According to our specification GDP in Poland depends in the long run on TFP in the euro area, which is consistent with the catching up process and the transmission of technology from the euro area to Poland through foreign direct investments and growing integration of the Polish economy within global value chains. The whole set of restrictions imposed on the cointegrating space has not been rejected by likelihood test for binding restrictions. The detailed estimation results for the VECM are presented in Table 1.

We use the residuals from the estimated VECM model to specify the structural shocks. To this end we impose the restrictions on the impact matrix as described above. We set $H^{\text {news }}=40$ and $H^{\text {sent }}=2$ in line with Barsky and Sims (2011) and Levchenko and Pandalai-Nayar (2020) respectively. This allows to identify the three structural shocks in the euro area-surprise and news technology shocks as well as the sentiment shock.

\footnotetext{
5 The forecast variable in our model is a forecast of annual GDP growth rate expected in period $t+2$ formulated in period $t$. By construction if the forecasters expect positive GDP growth the forecasted GDP level two periods ahead should be on average higher than the actual one.
} 
Table 1 Estimation results of the cointegrating relationships

\begin{tabular}{lllll}
\hline Dependent variable & $\mathrm{GDP}_{t}^{\mathrm{EA}}$ & $\mathrm{GDPF}_{t}^{\mathrm{EA}}$ & $\mathrm{INV}_{t}^{\mathrm{EA}}$ & $\mathrm{GDP}_{t}^{\mathrm{PL}}$ \\
\hline $\mathrm{TFP}_{t}^{\mathrm{EA}}$ & 1 & - & - & $4.559(1.376)$ \\
$\mathrm{GDP}_{t}^{\mathrm{EA}}$ & - & $1.092(0.016)$ & - & - \\
$\mathrm{HOURS}_{t}^{\mathrm{EA}}$ & $0.813(0.051)$ & - & - & - \\
$\mathrm{INTRATE}_{t}^{\mathrm{EA}}$ & - & - & $-0.016(0.003)$ & - \\
$\operatorname{GDPF}_{t}^{\mathrm{EA}}$ & - & - & $2.241(0.163)$ & - \\
LR test for binding restrictions: chi2(4) $=16.57(0.121)$ & &
\end{tabular}

Standard errors in parentheses

\section{Confidence and its spillovers}

This Section presents our main findings-how the estimated structural shocks work and what role they play in driving the business cycles in the euro area and in transmitting it to Poland. We begin by checking how the shocks work, and in particular, whether the reaction of the respective variables in the model to the sentiment shock is in line with the findings of Angeletos et al. (2018). Next, we investigate the role of the shocks in driving the business cycle in the euro area and analyze the transmission of shocks to Poland. We draw our main conclusions on the role of respective shocks by investigating the forecast error variance decomposition of GDP in the euro area and in Poland. We also split the impact of the euro area sentiment and news shocks on Poland's GDP into its direct and indirect effect. Finally we conduct a historical decomposition of GDP developments in both countries.

\subsection{Impulse responses}

The impulse response analysis has two goals. First the validation of our model. We check whether responses to the identified shocks are in line with economic intuition and, in particular, whether the sentiment shock has the desired properties. Second, we see if and how the spillovers work.

Figure 1 presents the impulse responses of all model variables to a surprise technology shock. As should be expected the reaction of TFP is immediate. This translates into higher consumption, investments and GDP in the euro area. For all these variables the reaction is highly persistent. In contrast, the interest rate does not change significantly. This seems to be in line with the specifics of a positive technology shock, which raises output but lowers inflation, sending contradictory signals to the central bank. Regarding spillovers, we observe a relatively strong reaction of Polish GDP. However, interestingly and in line with economic intuition, the response of the Polish economy lags that of the euro area-the transfer of technology takes time and this model feature can be considered as a positive validation of our identification strategy.

Impulse responses to the news technology shock are shown on Fig. 2. As in the previous case TFP, GDP, consumption and investments increase persistently. However, now the reaction of EA TFP occurs with a substantial lag (becomes significant only 
(a) Response of EA TFP to surprise technology shock

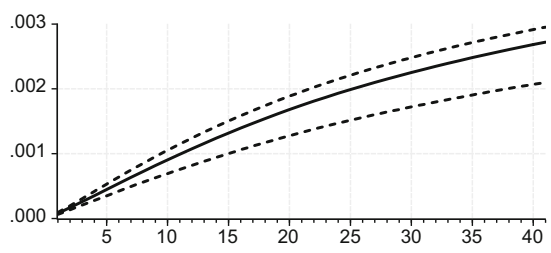

(c) Response of EA HOURS to surprise technology shock

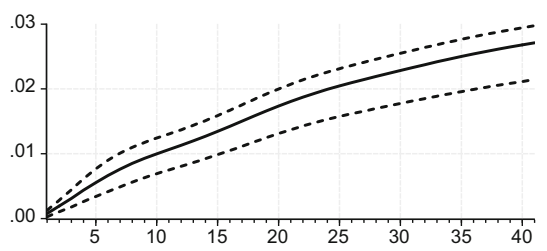

(e) Response of EA INV to surprise technology shock

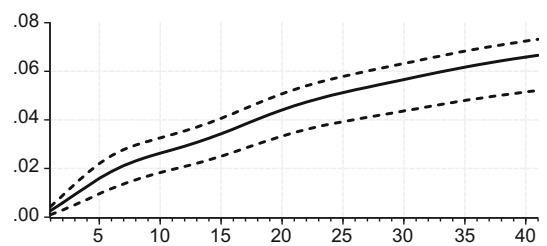

(g) Response of EA GDPF to surprise technology shock

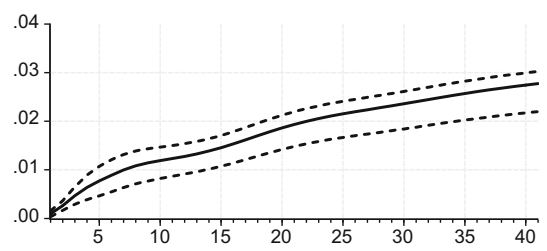

(b) Response of EA GDP to surprise technology shock

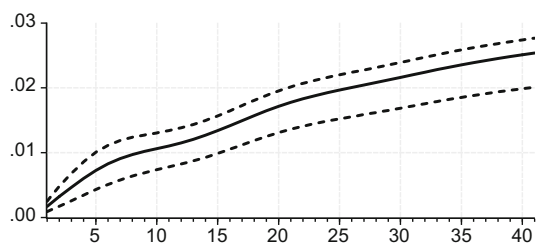

(d) Response of EA INT. RATE to surprise technology shock

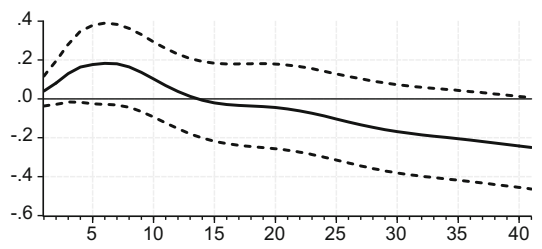

(f) Response of EA CONS to surprise technology shock

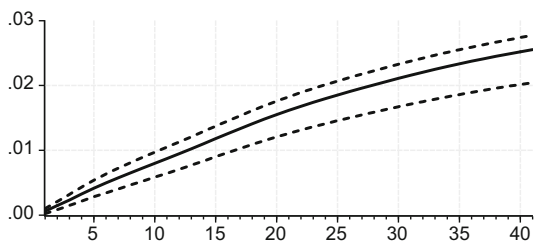

(h) Response of PL GDP to surprise technology shock

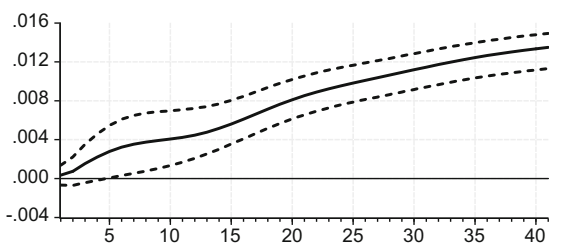

Fig. 1 The impulse responses to surprise technology shock. Note Dotted lines represent the 90\% bootstrap confidence bands calculated with 100000 replications, using the approach proposed by Hall (1992)

after 10 quarters). In contrast consumption, investments, hours and GDP react to the shock much faster than TFP, in line with the concept of an expected technology shock. Interestingly, the immediate reaction of Polish GDP is even stronger than that in the euro area. This suggests that economic news are transmitted not only via real economic linkages. Since we have only one variable for Poland we are not able to distinguish whether it is rather an effect on consumption or investment in anticipation of higher output that drives the result. 
(a) Response of EA TFP to news technology shock

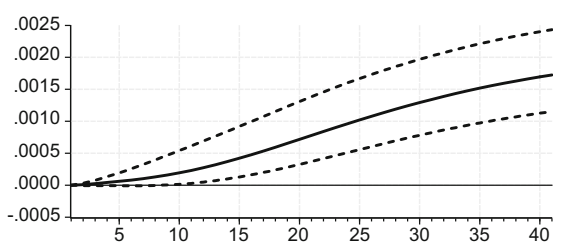

(c) Response of EA HOURS to news technology shock

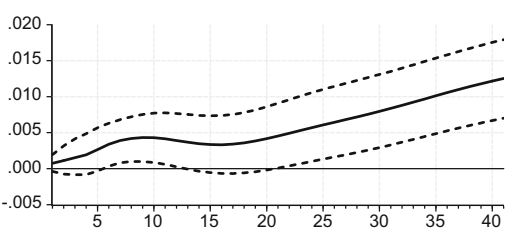

(e) Response of EA INV to news technology shock

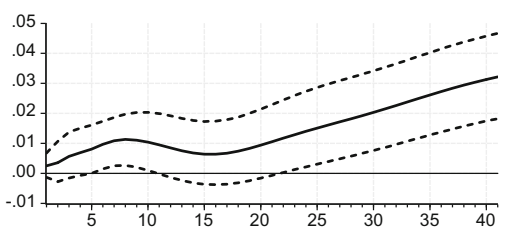

(g) Response of EA GDPF to news technology shock

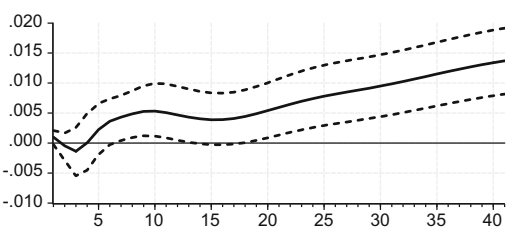

(b) Response of EA GDP to news technology shock

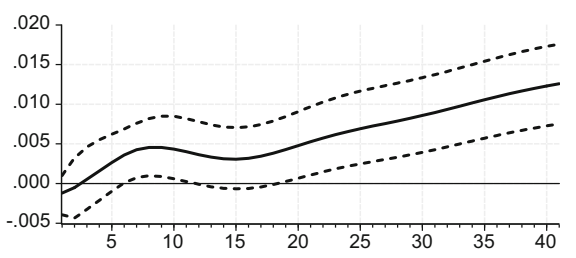

(d) Response of EA INT. RATE to news technology shock

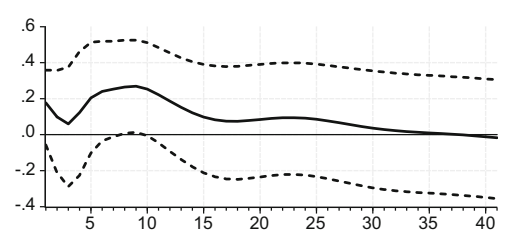

(f) Response of EA CONS to news technology shock

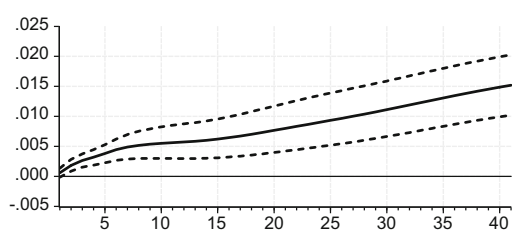

(h) Response of PL GDP to news technology shock

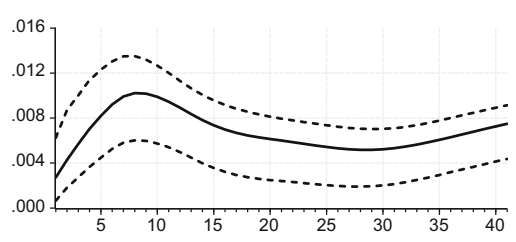

Fig. 2 The impulse responses to news technology shock. Note Dotted lines represent the $90 \%$ bootstrap confidence bands calculated with 100000 replications, using the approach proposed by Hall (1992)

Last but not least, we analyze the reactions to the euro area sentiment shock. This shock can be thought of as demand-type and thus should be expected to generate rather short-term reactions. This is indeed the case. The positive reaction of output, consumption, investments and hours is short-lived and dies out after approximately two years (Fig. 3). The central bank reacts by tightening monetary policy. There is a clear and fast spillover to Polish GDP which follows a very similar pattern. We observe a negative reaction of TFP to the sentiment shock - something that could be worrying. However, in economic terms the reaction is negligible $(0.01 \%)$, something confirmed by the variance decompositions discussed later.

As promised, we use the impulse responses to the sentiment shock to validate our identification strategy. In Angeletos et al. (2018) the sentiment shock generates a comovement of GDP, consumption, investments and hours worked-this is also the 
(a) Response of EA TFP to sentiment shock

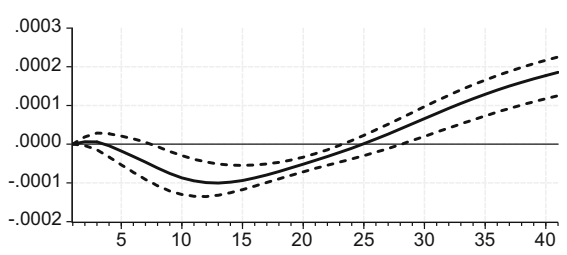

(c) Response of EA HOURS to sentiment shock

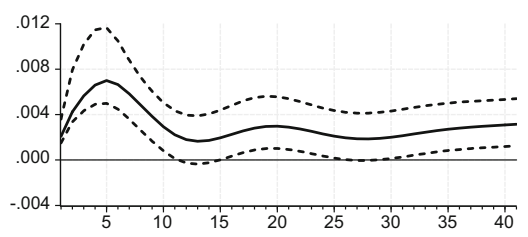

(e) Response of EA INV to sentiment shock

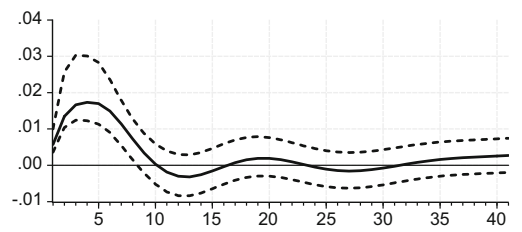

(g) Response of EA GDPF to sentiment shock

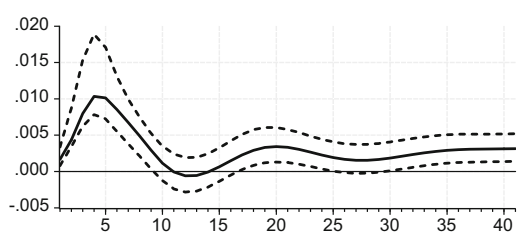

(b) Response of EA GDP to sentiment shock

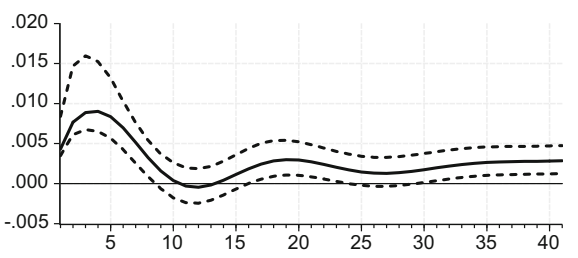

(d) Response of EA INT. RATE to sentiment shock

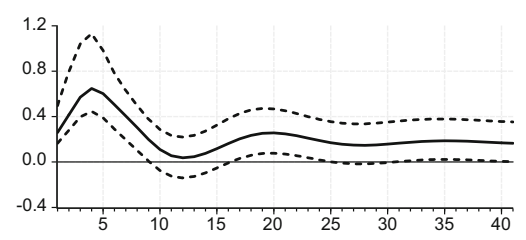

(f) Response of EA CONS to sentiment shock

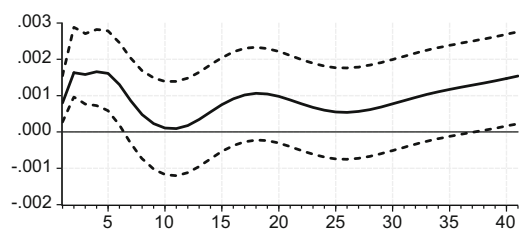

(h) Response of PL GDP to sentiment shock

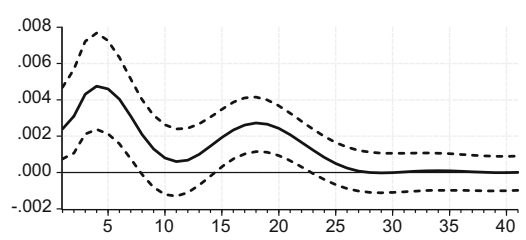

Fig. 3 The impulse responses to sentiment shock. Note Dotted lines represent the $90 \%$ bootstrap confidence bands calculated with 100000 replications, using the approach proposed by Hall (1992)

case in our model. It explains approximately half of the forecast error variance of GDP_-something we find as well (shown later). As pointed out by Angeletos et al. (2018) the reactions are not typical for other demand shocks known from the structural (New Keynesian DSGE) literature. For instance a time preference shock pushes consumption and investments in opposite directions, an expansionary monetary policy shock would lower the interest rate (which increases in our case) and a government spending shock would raise GDP but crowd out private expenditure. ${ }^{6}$ Our shock generates a short-lived economy-wide expansion, something hard to achieve with standard shocks in structural economic models, but easy to imagine in case of a positive swing

\footnotetext{
6 Financial shocks could possibly act in a similar fashion. However, as we show in Sect. 4 their inclusion does not change our main findings.
} 
Table 2 Forecast error variance decomposition of euro area TFP

\begin{tabular}{lllll}
\hline TFP & & & & \\
\hline Quarters & Surprise technology & News technology & Sentiment & Other \\
\hline 4 & 0.977 & 0.018 & 0.001 & 0.004 \\
8 & 0.953 & 0.038 & 0.003 & 0.006 \\
12 & 0.928 & 0.062 & 0.005 & 0.005 \\
24 & 0.847 & 0.150 & 0.002 & 0.002 \\
40 & 0.767 & 0.229 & 0.002 & 0.002 \\
\hline
\end{tabular}

Table 3 Forecast error variance decomposition of euro area GDP

\begin{tabular}{lllll}
\hline EA GDP & & & & \\
\hline Quarters & Surprise technology & News technology & Sentiment & Other \\
\hline 4 & 0.264 & 0.028 & 0.674 & 0.034 \\
8 & 0.431 & 0.074 & 0.443 & 0.052 \\
12 & 0.548 & 0.076 & 0.301 & 0.075 \\
24 & 0.757 & 0.072 & 0.125 & 0.046 \\
40 & 0.798 & 0.118 & 0.058 & 0.027 \\
\hline
\end{tabular}

in moods (sentiments). These considerations make us confident that what we identify is indeed a shock to economy-wide sentiments.

\subsection{Variance dempositions}

As a next step we discuss the forecast error variance decomposition (FEVD) of selected variables with respect to the contribution of the identified shocks. In the description below we concentrate on selected horizons only, but in tables and figures we present the detailed decomposition related to different horizons.

In line with our expectations the forecast error variance of TFP is affected almost entirely by technology shocks (Table 2). The contribution of the surprise technology shock to the variance of the forecast error amounts to $98 \%$ in the short horizon (4 quarters) and decreases to $77 \%$ in the long run (10years). In line with our earlier findings the news shock has a negligible impact on TFP in the short run, with lengthening of the forecast horizon its role increases to $23 \%$ for the 10 years ahead forecast.

What is more interesting is the decomposition of euro area GDP (Table 3). Here the situation is more nuanced. In the long run technology shocks dominate-in the 10 year horizon they explain almost $92 \%$ of the variance (with the surprise shock being more important than the news shock). However, at business cycle frequencies the bulk of GDP variability is driven by confidence. At the 12-quarter horizon the sentiment shock is responsible for $30 \%$ of output variance and the news technology shock for $8 \%$. It sums to $38 \%$, this being our synthetic measure of the role played by confidence shocks in the euro area at the 12-quarter horizon. 
Table 4 Forecast error variance decomposition of Poland's GDP

\begin{tabular}{lllll}
\hline Poland's GDP & & & & \\
\hline Quarters & Surprise technology & News technology & Sentiment & Other \\
\hline 4 & 0.030 & 0.432 & 0.210 & 0.328 \\
8 & 0.053 & 0.597 & 0.142 & 0.209 \\
12 & 0.077 & 0.642 & 0.106 & 0.175 \\
24 & 0.285 & 0.514 & 0.080 & 0.121 \\
40 & 0.532 & 0.360 & 0.042 & 0.065 \\
\hline
\end{tabular}

From this paper's point of view the most interesting results come now. The variance decomposition of Polish GDP (Table 4) reveals a number of findings. First, and not very surprisingly, the three shocks identified as coming from the euro area account for 67$93 \%$ of the variance. This shows that the role played by foreign developments in driving the Polish business cycle is huge. ${ }^{7}$ Second, confidence shocks play a pronounced role in generating spillovers, $40-75 \%$ of output variance is driven by the sentiment and news shocks (with news shocks being more important).

Let us now turn to the motivation of this paper. As shown in the Introduction the structural business cycle literature, in spite of modeling properly and carefully international trade relationships, is not able to come close to the scale of business cycle synchronization between countries. We hypothesized that the spillovers are to some extent due to confidence spreading in the ether-via media (including social ones) for example. The results presented thus far do not have a saying whether the spillovers are due to trade or other channels. It could be that they are entirely the effect of confidence shocks affecting euro area GDP and then impacting Poland via trade linkages. In such case our paper would say something new about the type of shocks that affect Poland, but not about the channels.

The next experiment sheds light on this issue. We calculate the FEVD of Polish GDP with respect to the confidence shocks after switching off their impact on euro area variables. Technically this amounts to setting selected elements of the impact matrix $C_{0}$ to zero, so that either the sentiment or the news shock has no impact on the euro area variables. Figures 4 and 5 present the FEVD to the news and sentiment shock divided into the direct (i.e., the one just calculated) and indirect (i.e., remaining, transmitted via euro area variables) impact on Polish GDP.

Regarding the technology news shock, in the short run the spillover happens mainly directly (i.e., via media). In the longer run, however, the role of indirect spillovers becomes more important. One interpretation of this finding could be that over time, as the new technology is put into operation real developments gain on importance, while their media coverage (and thus spillovers via media) become less pronounced.

The situation is different for sentiment shocks. In this case approximately $50 \%$ of the spillover happens directly independent of the horizon. This finding has an intuitive

\footnotetext{
7 Our finding seems in line with, e.g., Boschi et al. (2015) who use a GVAR approach and find that the contribution of foreign factors to forecast error variance decomposition of Poland's output amounts to ca. $60-80 \%$.
} 


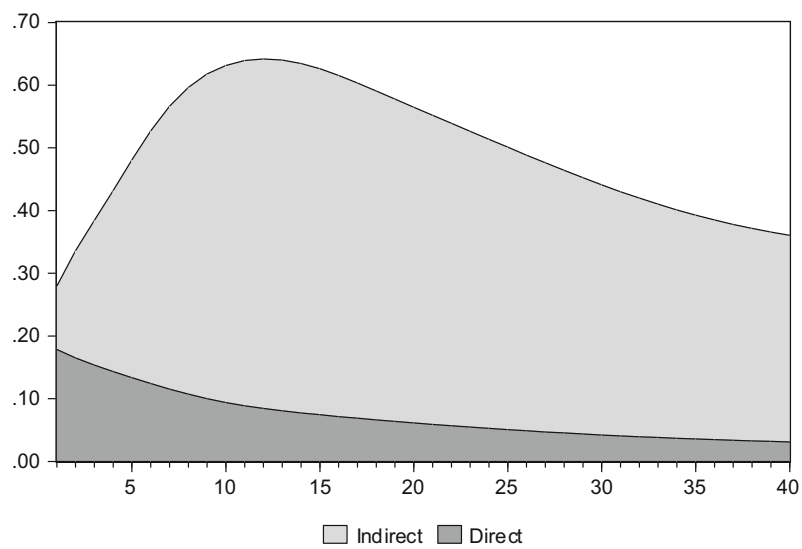

Fig. 4 Direct versus indirect impact of the news shock on the variability of Poland's GDP. Note The plot presents the contribution of the euro area news shock to Poland's GDP FEVD decomposed into its direct and indirect effects

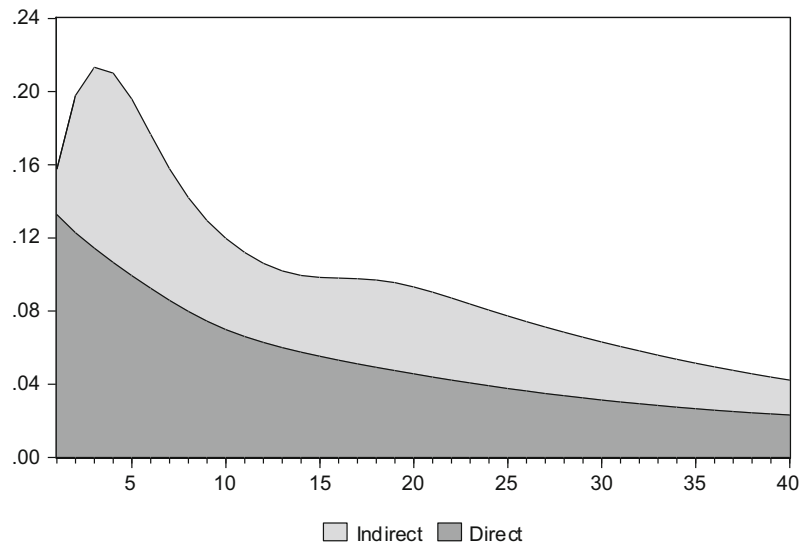

Fig. 5 Direct versus indirect impact of the sentiment shock on the variability of Poland's GDP. Note The plot presents the contribution of the euro area sentiment shock to Poland's GDP FEVD decomposed into its direct and indirect effects

interpretation too. The sentiment shock has no supply-side effects and remains a mediatype shock over its lifetime. As a result its transmission to Poland happens to a large extent via media as well.

The total contribution of direct spillovers to Poland's GDP volatility amounts to $25 \%$ at the 4-quarter horizon, and (not surprisingly) declines over time (Table 5).

\subsection{Historical decompositions}

Variance decompositions speak about the average role of shocks in the sample. In contrast, historical decompositions allow to investigate the role played by various shocks in shaping model variables in each and single quarter. Below we discuss the 


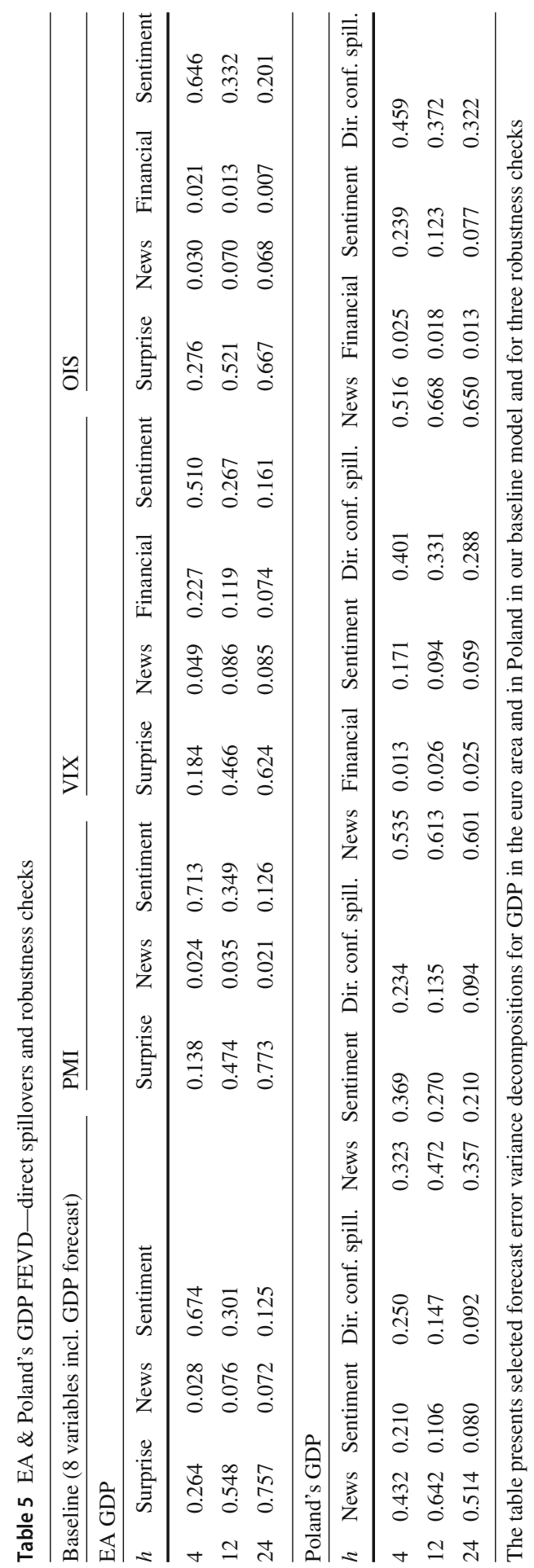




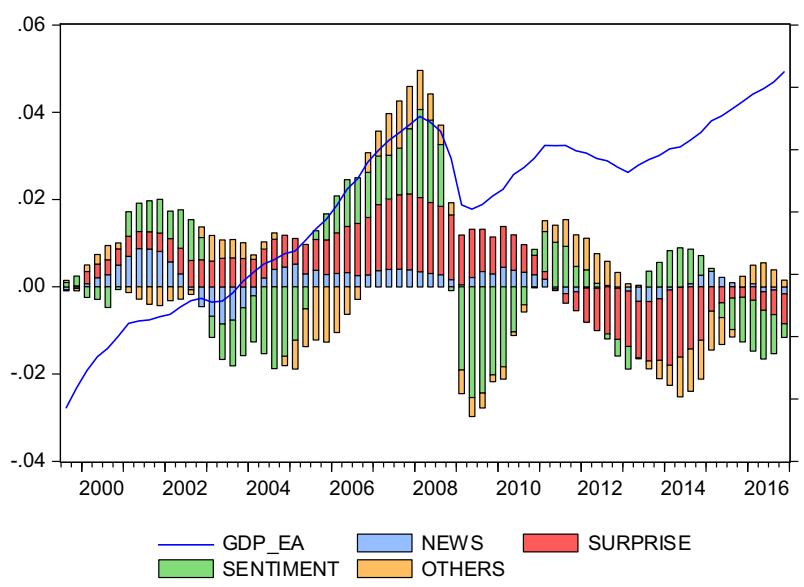

Fig. 6 Historical decomposition of euro area GDP. Note The plot presents the historical decomposition of euro area GDP with respect to structural shocks

historical decompositions of euro area and Poland's GDP, concentrating on the most important developments. On the one hand this analysis sheds light on the factors that drove the business cycles with a particular emphasis on confidence shocks. On the other, the findings can also be seen as another form of validating our modeling strategy.

Let us first focus on euro area GDP. Figure 6 presents its decomposition into the contributions of all shocks (unidentified shocks have been grouped and labeled "other"). As already shown in the previous subsection, the most important shock at business cycle frequency is the sentiment shock. This is also consistent with the historical decomposition. To facilitate its interpretation Fig. 7 plots the Economic Sentiment Indicator in the euro area (note that this variable was not used in the estimation process). Contribution of the sentiment shock to GDP growth becomes deeply negative between 2003 and 2004, which probably reflects the downward swing in moods that followed the stock market crash. Sentiment became again a driver of output between 2005 and 2008, probably following the record readings of the sentiment indicator and the booming housing markets. The onset of the global financial crisis is identified by the model as the occurrence of a large and persistent negative sentiment shock. This shock has a negative contribution to GDP since mid-2008 until the end of 2010. In 2011 it rebounds and raises economic growth and then turns negative again in 2012this coincides with a deterioration in moods following the euro area debt crisis. The last event with an interesting economic interpretation is the positive contribution of sentiment shocks to GDP in 2013-2014 which most probably follows the improvement of the overall economic sentiment in the euro area that was a lagged effect of the announcement in late 2012 of Outright Monetary Transactions by the European Central Bank which calmed financial markets and substantially brought down country risk premia.

Turning to the surprise technology shock, its contribution to euro area GDP is mainly positive up to 2010 which may be associated with the ongoing globalization 


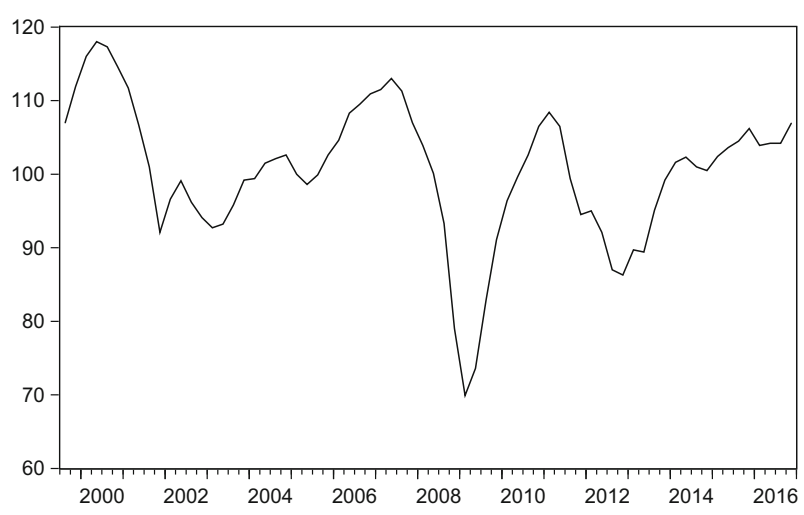

Fig. 7 Economic sentiment indicator in the euro area. Note The plot presents the Economic Sentiment Indicator in the euro area (Source: European Commission)

process of that time (plus the lag between the shock and its strongest impact on GDP of approximately 3 years). In 2011 the contribution of this shock started to be negative as a consequence of the financial crisis which affected investment plans of the corporate sector. The most significant and negative impact of the surprise shock is identified in years 2012-2015 which may be associated with supply-side problems known as "secular stagnation" and the reversal of the globalization process.

In line with the FEVD results, the role of the news shock for short-run fluctuations is not very important. It has a mostly positive impact on GDP until 2010, which may be interpreted as a (partly delayed) effect of the positive feelings about IT improvements impact on TFP prevailing in the 1990s and 2000s. After 2010 the shock does not play a significant role.

Turning to the decomposition of Polish GDP (Fig. 8) it has to be born in mind that all structural shock in our model come from the euro area and only their transmission to Polish GDP differs somewhat from the transmission to EA GDP. As a result it is not very surprising that the factors behind the Polish business cycle are similar to those described above. As in the case of the euro area we can observe the boom-bust swing in sentiments shortly before and immediately after the crisis and the more persistent effects of current and expected future technology improvements.

\section{Robustness}

This Section investigates the robustness of our results to various assumptions. We begin with checking whether our choice of the forward-looking variable matters substantially for the findings. To this end we substitute the GDP forecast with the Purchasing Managers Index (PMI) for the euro area. The variance decomposition of EA and Polish GDP for selected horizons is presented in Table 5. While the specific numbers differ slighly from our baseline estimation, the main message remains unchangedconfidence shocks matter both for fluctuations in the euro area and for the spillover to 


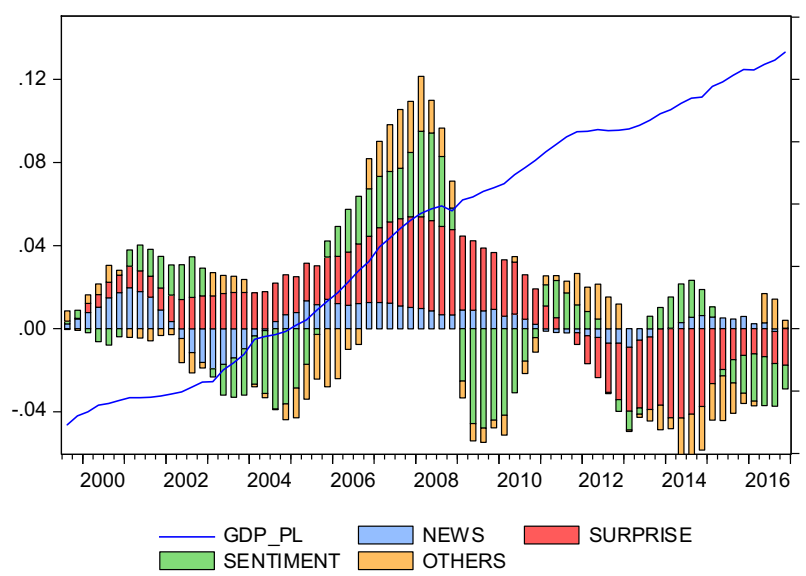

Fig. 8 Historical decomposition of Poland's GDP. Note The plot presents the historical decomposition of Poland's GDP with respect to structural shocks

Poland. The direct spillover is similar to our baseline case, and with a $23 \%$ share in GDP FEVD in the short run can be considered substantial.

Second, as written in Sect. 3.1, our sentiment shock could possibly be confused with a financial shock. Below we offer a formal investigation into this matter. Given the limited sample size our baseline model with eight variables should be considered large and we would not feel comfortable extending it for any additional variables that might be necessary to identify financial shocks. Instead we decided to proceed as follows - we dropped three variables that do not seem crucial to extract the technology and sentiment shock (consumption, investments and the interest rate) but were rather used to validate them. On their place we include a variable that contains information about financial frictions and reestimate the model. Then we identify four shocks-first the two technology shocks, than a financial shock that (given the previous shocks) maximizes the FEVD of the financial variable and finally the sentiment shock that given the previous shocks maximizes the FEVD of the GDP forecast.

We use two alternative financial variables: the VIX index and the Euribor-Overnight Index Swap spread. Both are standard indicators of financial tensions, the first with a more global flavor, the second being euro area oriented. Table 5 presents selected aspects of the variance decomposition. The financial shock matters somewhat for cyclical fluctuations explaining up to $7-23 \%$ of GDP variance in the euro area (and a significantly lower share in Poland) in the model with VIX and even less in the model with OIS. Regarding spillovers, changing the model does not affect the results substantially - at the 4-quarter horizon the sentiment shock still explains approximately $20 \%$ and the news shock 50\% of the FEVD of Polish GDP. Direct spillovers of confidence shocks increase somewhat and account for 30-45\% of GDP fluctuations, depending on the horizon. It should also be noted that modifying the identification method did not influence the sentiment shock as such. For instance the correlation between the sentiment shock identified in the baseline model and in the model including the VIX is 0.80 . 
Third we investigate deeper whether the spillovers of news and sentiment shocks that we identified as "direct" are not transmitted through the trade channel. Therefore analogously as in the previous robustness check we include an additional variable, which captures the trade integration of Poland with the euro area and drop three less important variables. The trade integration variable is constructed as the ratio of the sum of Poland's exports and imports to and from the euro area to Poland's GDP. Accordingly when calculating the direct confidence spillovers from the euro area to Poland we switch off their impact not only on euro area variables but also on the trade integration variable to isolate the direct spillover. The variance decomposition of euro area GDP is very close to the decomposition in our baseline model (Table 6). Regarding Poland's GDP variance decomposition we find that the contribution of the sentiment shock becomes higher. The direct spillover of both confidence shocks is higher as well.

Next, in a similar vein, we examine the role of financial integration in the transmission of confidence shocks. We add to our model a variable representing the financial integration of Poland with the rest of the world: the ratio of external liabilities to total liabilities of monetary financial institutions in Poland. We isolate the direct spillovers of confidence shocks stemming from the euro area to Poland by switching off their impact on euro area variables as well as on the measure of financial integration. We find that the forecast error variance decomposition of the euro area GDP reveals a similar pattern as the respective decomposition in our baseline model (Table 6). Also the decomposition of the forecast error variance of Poland's GDP does not differ much from the baseline model with a slightly higher contribution of the sentiment shock only. The overall contribution of the direct spillovers of the euro area confidence shocks to Poland's GDP forecast error variance is comparable to their contribution in the baseline model in the short horizon and higher in the longer one.

Finally, we check to what extent the confidence shocks stemming from the euro area affect the confidence of economic agents in Poland. Therefore, as before we extend our baseline model by a measure of confidence: the Economic Sentiment Indicator (ESI) published by the European Commission. ESI is a composite indicator, which covers all main sectors of the economy and is computed using surveys conducted among both producers and consumers. ${ }^{8}$ We find that in contrast to Poland's GDP, the forecast error variance of ESI is affected to a larger extent by the sentiment shocks than by news shocks (Table 7). Moreover the direct spillovers of the euro area confidence shocks contribute to larger extent to the forecast error variance of ESI (30-40\%) than to Poland's GDP (10-25\%) which is quite intuitive - the transmission via media first influences sentiments in Poland and only then (hence to a smaller degree) Polish GDP. We treat this robustness check as another indirect confirmation that we properly identify confidence shocks and their transmission channels (direct vs. indirect) to Poland.

All in all, our robustness checks, while changing somewhat the specific numbers, do not undermine our main finding - confidence shocks matter a lot for business

\footnotetext{
8 The detailed methodological guidelines are published on the European Commission website: https://ec. europa.eu/info/files/user-guide-joint-harmonised-eu-programme-business-and-consumer-surveys_en.
} 


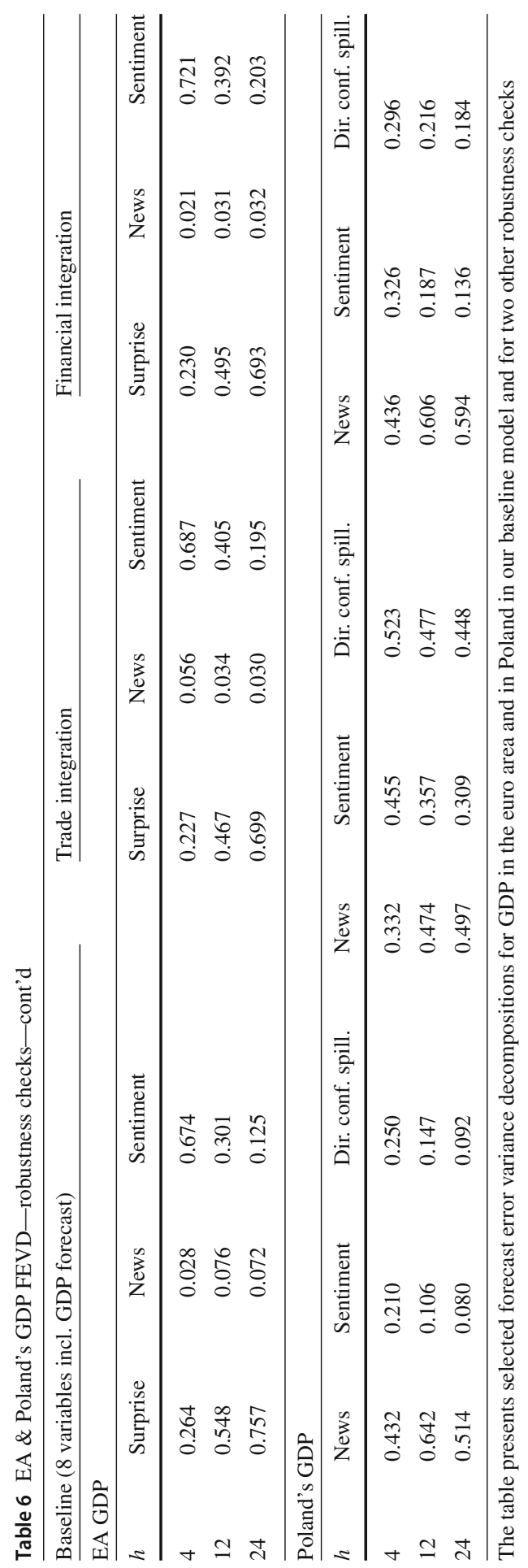


Table 7 Poland's ESI FEVD

\begin{tabular}{|c|c|c|c|c|c|c|}
\hline \multicolumn{4}{|c|}{ Baseline (8 variables incl. GDP forecast) } & \multicolumn{3}{|c|}{ Model incl. PL ESI conf. indicator } \\
\hline \multicolumn{4}{|c|}{ Poland's GDP FEVD } & \multicolumn{3}{|c|}{ Poland's ESI FEVD } \\
\hline$h$ & News & Sentiment & Dir. conf. spill. & News & Sentiment & Dir. conf. spill. \\
\hline 4 & 0.432 & 0.210 & 0.250 & 0.025 & 0.679 & 0.417 \\
\hline 12 & 0.642 & 0.106 & 0.147 & 0.141 & 0.439 & 0.310 \\
\hline 24 & 0.514 & 0.080 & 0.092 & 0.100 & 0.267 & 0.208 \\
\hline
\end{tabular}

The table presents forecast error variance decompositions for GDP in Poland in our baseline model and FEVD for Poland's ESI confidence indicator in the model extended by ESI variable for Poland

cycle fluctuations and their international spillovers. Moreover, a substantial part of the spillovers happens directly, e.g., via media.

\section{Conclusions}

How important are confidence fluctuations for business cycles? How important are they for spillovers of cyclical fluctuations between economies? Are they transmitted internationally via traditional channels (trade, finance) or rather via media? These questions seem fundamental to understand the nature of business cycle fluctuations. They relate to the old idea of Pigou (1927) and Keynes (1936) that fluctuations in moods have a potential to drive business cycles. This view has recently gained substantial attention in the literature and most existing research points to a very important role of confidence fluctuations in driving domestic business cycles. More importantly however, we believe that moods can also travel across borders, thus strengthening the international correlation of business cycles. Moreover, we believe that this may, to some extent, happen directly (e.g., via media), and not only indirectly (via trade or financial linkages). This idea has so far been almost untested in the literature and we believe to have a genuine contribution in this area.

This paper offers an empirical approach to answering the questions above. We estimate a VAR/VECM model for the euro area and Poland (a large and a small, neighboring economy) and carefully identify shocks related to confidence fluctuations. We distinguish two types of confidence shocks. The first type relates to the supply side of the economy and can be interpreted as expectation of future improvements in technology (it is called technology news). The second type has a demand flavor and can be interpreted as fluctuations in moods about future economic performance, unrelated to technological advance (we call it sentiment).

Confidence shocks steming from the euro area play an important role both in the euro area and in Poland. For instance, at the 12-quater horizon they account for almost $40 \%$ of forecast error variance decomposition of GDP in the euro area and their spillover to Poland accounts for over $70 \%$ of its GDP variability. We also divide the international transmission of confidence into a direct and indirect effect. The latter operates by first affecting euro area variables and then transmitting to Poland (probably mainly via trade or finance). The former affects Poland directly, presumably due to 
spreading news (e.g., via media). In the short run the direct channel is responsible for approximately $50 \%$ of the confidence spillovers. In the loger run indirect channels take over. We put this result at the forefront of our findings, since it points to an important role of a channel that has, so far, been neglected in the structural international business cycle literature.

Open Access This article is licensed under a Creative Commons Attribution 4.0 International License, which permits use, sharing, adaptation, distribution and reproduction in any medium or format, as long as you give appropriate credit to the original author(s) and the source, provide a link to the Creative Commons licence, and indicate if changes were made. The images or other third party material in this article are included in the article's Creative Commons licence, unless indicated otherwise in a credit line to the material. If material is not included in the article's Creative Commons licence and your intended use is not permitted by statutory regulation or exceeds the permitted use, you will need to obtain permission directly from the copyright holder. To view a copy of this licence, visit http://creativecommons.org/licenses/by/4.0/.

\section{References}

Angeletos G-M, La’O J (2013) Sentiments. Econometrica 81(2):739-779

Angeletos G-M, Collard F, Dellas H (2018) Quantifying confidence. Econometrica 86(5):1689-1726

Backus DK, Kehoe PJ, Kydland FE (1992) International real business cycles. J Polit Econ 100(4):745-775

Barsky RB, Sims ER (2011) News shocks and business cycles. J Monet Econ 58(3):273-289

Barsky RB, Sims ER (2012) Information, animal spirits, and the meaning of innovations in consumer confidence. Am Econ Rev 102(4):1343-1377

Beaudry P, Portier F (2004) An exploration into Pigou's theory of cycles. J Monet Econ 51(6):1183-1216

Beaudry P, Portier F (2006) Stock prices, news, and economic fluctuations. Am Econ Rev 96(4):1293-1307

Beaudry P, Dupaigne M, Portier F (2011) Modeling news-driven international business cycles. Rev Econ Dyn 14(1):72-91

Blanchard OJ, L'Huillier J-P, Lorenzoni G (2013) News, noise, and fluctuations: an empirical exploration. Am Econ Rev 103(7):3045-3070

Boschi M, Marzo M, Salotti S (2015) Domestic versus international determinants of European business cycles: a GVAR approach. Empir Econ 49(2):403-421

Brzoza-Brzezina M, Kolasa M, Makarski K (2018) Crisis, contagion and international policy spillovers under foreign ownership of banks. J Financ Stabil 36:293-304

DeGrauwe P, Ji Y (2017) The international synchronisation of business cycles: the role of animal spirits. Open Econ Rev 28(3):383-412

Eusepi S, Preston B (2011) Expectations, learning, and business cycle fluctuations. Am Econ Rev 101(6):2844-2872

Fujiwara I, Hirose Y, Shintani M (2011) Can news be a major source of aggregate fluctuations? A Bayesian DSGE approach. J Money Credit Bank 43(1):1-29

Gong C, Kim S (2018) Regional business cycle synchronization in emerging and developing countries: regional or global integration? Trade or financial integration? J Int Money Finance 84(C):42-57

Ha J, Raju H, Ayhan Kose M, Ohnsorge FL, Sugawara N (2020) Understanding global confidence cycles. mimeo, International Monetary Fund and World Bank

Hall P (1992) The bootstrap and Edgeworth expansion. Springer series in statistics. Springer, Berlin

Havik K, Mc Morrow K, Orlandi F, Planas C, Raciborski R, Roeger W, Rossi A, Thum-Thysen A, Vandermeulen V (2014) The production function methodology for calculating potential growth rates \& output gaps. European Economy-Economic Papers 2008-2015 535, Directorate General Economic and Financial Affairs (DG ECFIN), European Commission

Jaimovich N, Rebelo S (2009) Can news about the future drive the business cycle? Am Econ Rev 99(4):10971118

Justiniano A, Preston B (2010) Can structural small open-economy models account for the influence of foreign disturbances? J Int Econ 81(1):61-74 
Kamber G, Theodoridis K, Thoenissen C (2017) News-driven business cycles in small open economies. J Int Econ 105(C):77-89

Keynes JM (1936) The general theory of employment, interest and money. Macmillan, New York

Levchenko AA, Pandalai-Nayar N (2020) TFP, news, and "sentiments": the international transmission of business cycles. J Eur Econ Assoc 18(1):302-341

Milani F (2017) Sentiment and the U.S. business cycle. J Econ Dyn Control 82(C):289-311

Olivero MP (2010) Market power in banking, countercyclical margins and the international transmission of business cycles. J Int Econ 80(2):292-301

Pigou AC (1927) Industrial fluctuations. Macmillan and Company, limited, New York

Schmitt-Grohe S, Uribe M (2012) What's news in business cycles. Econometrica 80(6):2733-2764

Stanisic N (2013) Convergence between the business cycles of Central and Eastern European countries and the Euro area. Balt J Econ 13:63-74

Uhlig H (2004) What moves GNP? Econometric Society 2004 North American Winter Meetings 636, Econometric Society

Wu JC, Xia FD (2016) Measuring the macroeconomic impact of monetary policy at the zero lower bound. J Money Credit Bank 48(2-3):253-291

Publisher's Note Springer Nature remains neutral with regard to jurisdictional claims in published maps and institutional affiliations. 